\title{
FACES CAMP DE EVA PERÓN PARA UM BIOGRAFEMA HOMOCULTURAL
}

André Luis Mitidieri (UESC)

Resumo: Amparados em pesquisa bibliográfica, fundamentada nos aportes teóricos de Beatriz Sarlo, Denilson Lopes, Roland Barthes e Susan Sontag, definimos o biografema homocultural camp e o relacionamos à protagonista do romance Santa Evita, de Tomás Eloy Martínez (1995), bem como a intervenções críticas do autor sobre outras representações de Eva Perón.

Palavras-chave: Biografema homocultural, Camp, Santa Evita, Tomás Eloy Martínez.

Resumen: Con base en investigación bibliográfica, fundamentada en los aportes teóricos de Beatriz Sarlo, Denilson Lopes, Roland Barthes e Susan Sontag, definimos el biografema homocultural camp y lo relacionamos a la protagonista de la novela Santa Evita, de Tomás Eloy Martínez (1995), así como también a invervenciones críticas del mismo autor sobre otras representaciones de Eva Perón.

Palabras-clave: Biografema homocultural, Camp, Santa Evita, Tomás Eloy Martínez.

O modo como o sujeito-autor se posiciona no discurso da crítica contemporânea pode variar: alguns adotam posição de distanciamento, e outros se entrelaçam ao corpus escolhido, acompanhando o movimento de entrada e saída do gesto enunciativo. Viabilizam-se olhares diferenciados a gêneros menores, a uma tradição literária desviada do foco das grandes narrativas, processados através das margens e dos bastidores. Os centros acadêmicos não mais definem 
os critérios de preferência e valores estéticos, ao mesmo tempo em que o momento atual apresenta critérios híbridos e mais abrangentes: "os cânones e a tradição literária atuam sorrateiramente sobre a experiência singular do fazer artístico, atividade secular que se nutre de revivals e revisitações" (SOUZA, 2002, p. 90).

Ao mesmo tempo, a proliferação de práticas discursivas tidas como extrínsecas à literatura, por exemplo, a

cultura de massa, as biografias, os acontecimentos do cotidiano, além da imposição de leis regidas pelo mercado, representam uma das marcas do nosso tempo, que traz para o interior da discussão atual, a democratização dos discursos. (SOUZA, 2002, p. 90)

Nesse conjunto, e após longo expurgo por boa parte do século $X X$, a abordagem biográfica retorna aos estudos históricos, porém, não mais voltada às ações dos "grandes vultos da história", muito menos por intermédio da mera inserção de personalidades desse tipo em seus respectivos contextos, buscando analisar os principais eventos nos quais poderiam estar envolvidas.

De outro modo, os estudos histórico-biográficos contemporâneos têm em mente as relações entre acontecimentos, conjunturas e estruturas, elites e massas, 
indivíduos e grupos, palavra e ação. É pensando também na reestruturação do próprio gênero biográfico, de suas formas e de seus meios de viabilização nos estudos históricos, que François Dosse (2007) escreve La apuesta biográfica: escribir una vida. Nesse livro, destaca o conceito de "biografema", estabelecido pelo teórico homossexual Roland Barthes (1971) quando aborda as representações pela linguagem através de um conceito tributário da noção de fonema:

Se eu fosse um escritor, já morto, como gostaria que minha vida se reduzisse, pelos cuidados de um biógrafo amigo e desenvolto, a alguns pormenores, a alguns gostos, a algumas inflexões, digamos: 'biografemas', cuja distinção e mobilidade poderiam viajar fora de qualquer destino e vir tocar, à maneira dos átomos epicurianos, algum corpo futuro, prometido à mesma dispersão; uma vida furada, em suma, como Proust soube escrever a sua na sua obra, ou então um filme à moda antiga, de que está ausente toda palavra e cuja vaga de imagens (esse flumen orationis em que talvez consista 'o lado porco' da escritura é) entrecortada, à moda de soluços salutares, pelo negro apenas escrito do interstício, a irrupção desenvolta de outro significante: o regalo branco de Sade, os vasos de flores de Fourier, os olhos espanhóis de Inácio. (BARTHES, 1971, p. 12) 
Vidas vividas juntam-se a sinais diversos, imagens, resíduos sígnicos, também a indagarem sobre a realidade, nos corpúsculos biografemáticos que Barthes (1990) detecta em Fourier: "seu gosto pelos 'mirlitons' (bolinhos parisienses com aromatizantes), sua simpatia tardia pelas lésbicas, sua morte entre os vasos de flores" (1990, p. 11). Essas formas residuais, esses cacos particulares da existência, depõem acerca do sujeito de uma forma singular:

o que me vem de Loyola não são as peregrinações, as visões, as macerações e as constituições do santo, mas somente os seus belos olhos, sempre um pouco marejados de lágrimas. Porque, se é necessário que, por uma retórica arrevesada, haja no Texto, destruidor de todo sujeito, um sujeito para se amar, tal sujeito é disperso, um pouco como as cinzas que se atiram ao vento após a morte (ao tema da urna e da estela, objetos fortes, fechados, instituidores de destino, opor-se-iam os cavacos de lembrança, a erosão que só deixa da visa passada alguns vincos). (BARTHES, 1990, p. 12)

Tais vestígios permitem refigurar as muitas histórias que poderiam ter ocorrido e nem tão somente a história estabelecida. Operações metonímicas como as que se viabilizam por meio do conceito de biografema somam-se tanto às considerações atuais, quanto a uma historiografia 
da literatura que se nega à canonicidade fixa ou presa a um só contexto. Daí a presente atenção aos lugares móveis dos textos e seus sentidos, em lugar dos enquadramentos unânimes, nacionais, lineares, uniculturais.

É assim que buscamos articular a ideia barthesiana de biografema à crítica cultural contemporânea, a fim de desenvolvermos a noção de "biografema homocultural" a partir do romance Santa Evita, de Tomás Eloy Martínez (2006), num momento em que o contexto histórico e suas interpretações auxiliam a compreender tudo aquilo que, à primeira vista, pode parecer inexplicável ou desconcertante. Lidando com modelos divergentes, associamo-nos à reflexão sobre as diferenças entre um espelho (no singular) e os espelhos (no plural); quer se disponham "um em face do outro (imagem zen), de maneira a refletirem sempre o vazio, quer a multiplicidade dos espelhos justapostos cerque o sujeito com uma imagem circular cujo vaivém fica por isso mesmo abolido" (BARTHES, 1990, p. 129).

O caráter não linear do biografema fundamenta-se na mobilidade e na fluidez, oferecendo sinais entrecortados que proporcionam a materialização ou as interpretações da multiplicidade do indivíduo e das sociedades. O conceito ganha destaque no sistema de pensamento do 
estudioso francês e nos estudos (auto)biográficos que, após longo ostracismo, voltam à cena teórica francesa em meados dos anos 1970. Tamanha importância adquire a noção barthesiana nesse contexto, de onde migra com sucesso aos centros universitários ocidentais, que retorna em livro publicado originalmente no ano de 1980, Câmara clara, estritamente vinculada com aquele instante ímpar de um sujeito, captado pela fotografia quando,

às vezes, faz aparecer o que jamais percebemos de um rosto real (ou refletido em um espelho): um traço genético, o pedaço de si mesmo ou de um parente que vem de um ascendente. Em tal foto, tenho o 'focinho' da irmã de meu pai. A Fotografia dá um pouco de verdade, com a condição de retalhar o corpo. Mas essa verdade não é a do indivíduo, que permanece irredutível; é a da linguagem. (BARTHES, 1984, p. 153)

Para definir um dos vastos elementos capazes de explicar o interesse despertado por fotografias que, portadoras de um afeto médio, se fazem perceber com familiariade devido à cultura moral e política ou ao saber do observador, mas sempre enviam a uma informação clássica, Barthes utiliza-se do termo latino studium,

que não quer dizer, pelo menos de imediato, 'estudo', mas a aplicação 
a uma coisa, o gosto por alguém, uma espécie de investimento geral, ardoroso, é verdade, mas sem acuidade particular. (1984, p. 45)

O segundo elemento parte da cena, à maneira de uma flecha; nomeado como punctum,

é também picada, pequeno buraco, pequena mancha, pequeno corte - e também lance de dados. O punctum de uma foto é esse acaso que, nela, me punge (mas também me mortifica, me fere). (BARTHES, 1984, p. 46)

Em contraste com o studium, o punctum expressa a "zebrura inesperada que às vezes vinha atravessar esse campo" (BARTHES, 1984, p. 141) e, ao se desprender do detalhe, não sendo mais uma questão "de forma, mas de intensidade, é o Tempo, é a ênfase dilaceradora do noema ('isso foi'), sua representação pura" (BARTHES, 1984, p. 141). Tanto num, quanto em outro caso, o punctum se associa intimamente ao biografema, aqui conjugado à "homocultura" como lócus de estudo e representação de expressões culturais produzidas por sujeitos homossexuais e/ou a seu respeito, bem como das visões e dos diálogos que proporcionam, desde a ruptura aos discursos hegemônicos e da crítica às heteronormatividades.

Nesse âmbito, representações biográficas, históricas 
e literárias de Eva Perón elaboradas por Juan José Sebreli (1966), Manuel Puig (1966), Osvaldo Lamborghini (1969) e Raúl Natalio Roque Damonte Botana Taborda, o Copi (1970), mostravam as ambivalências do fetiche evocado pelo nome de Eva. Entre a "guerra suja" (1976 - 1983) que marcou a era ditatorial na Argentina e a futura redemocratizaçãodo país, novos acréscimos a sua imagem; alguns que satisfazem curiosidades privadas; outros que mais ainda a deslocam às margens da sociedade militarizada e patriarcal, sobressaem nos textos de autoria homossexual dedicados à "Dama da Esperança" por seu costureiro Paco Jaumandreu (1975; 1981), pela poetisa María Elena Walsh (1976) e pelo escritor Néstor Perlongher (1975, 1980, 1983, 1989).

David William Foster ressalta, dentre as várias configurações assumidas pelo ícone de Evita no imaginário social do Rio da Prata, a sua identificação como figura de proa para a cena LGBTs no período pós-ditatorial:

'Si Evita viviera, seria tortillera'. Con este tropo, tomado del grito de combate del movimiento guerrillero de la izquierda argentina, 'Si Evita viviera, sería montonera', el naciente movimiento gay de los ochenta (el cual fue posible solamente gracias a la redemocratización de la post-dictadura y la determinación de Argentina de ser absolutamente moderna) intentó reclamar a Eva Duarte 
de Perón como un potente símbolo. ${ }^{1}$ (1999, p. 529)

O desvelamento da mulher como um "ícone da inscrição da Argentina no texto da modernidade periférica", conforme lembra Susana Rosano (2005), fundamentada em Beatriz Sarlo (1988), torna-se paralela a sua atuação, primeiramente como atriz e mais tarde como liderança política que usou e abusou dos meios de comunicação de massa, principalmente, do rádio. Seu desempenho nos palcos do poder e muitas imagens daí decorrentes filiam-se ao camp, sensibilidade estética da arte popular que, logo apropriada pela indústria cultural, se assinala pelo exagero, pela inaturalidade e por certa transformação do sério em banal:

estaria mais na esfera do brega assumido, sem culpas, tão presente nos exageros de muitos dos ícones da MPB, especialmente o culto a certas cantoras e seus fãs. (LOPES, 2002, p. 95)

É o que se verifica com Eva Perón que, de corpo entrelaçado a uma experiência coletiva, com papel fundamental na entrada do peronismo em cena e na inscrição do populismo platino junto ao imaginário modernizador nacional, se transforma em artifício extraordinário, a marcar um estilo desmesurado e:

1 '“Se Evita vivesse, seria sapatão'. Com esse tropo, tomado de empréstimo do grito de combate do movimento guerrilheiro da esquerda argentina, 'Se Evita vivesse, seria montonera', o nascente movimento gay dos anos 1980 (que se fez possível graças somente à redemocratização da pós-ditadura e à determinação da Argentina a ser absolutamente moderna) tentou reclamar Eva Duarte de Perón como um potente símbolo" (FOSTER, 1999, p. 529, tradução nossa). 
se articula a una serie de indagaciones experimentales que eligen interrogar al personaje desde una pregunta desestabilizadora: su condición de mujer. Desde allí surgen reinvenciones que paradójicamente convierten a este ícono del nacionalismo en una figura marginal de tintes posmodernos. El performance de Evita se reviste así con los colores estridentes de la estética camp y de allí surgen imágenes sorprendentes de una Eva travesti, lumpen, fiestera, absolutamente marginal a las sintaxis explicativas que previamente habían articulado los discursos tanto de la ortodoxia peronista como de la oposición libera. (ROSANO, 2005, p. 274-275)

Levando isso em conta, a ideia de "biografema homocultural" permite-nos analisar a tradução brasileira de Santa Evita (1996), na qual, durante uma de suas várias inserções metatextuais, Tomás Eloy Martínez informa que, em Eva Perón, drama de Copi encenado pela primeira vez em Paris no ano de 1970, "Evita mostrava a bunda. Na peça ela oferece seu amor como pode ou como sabe" (1996, p. 173). Entretanto, trata-se de um poder amputado e de um saber

2 “[...] articula-se a uma série de indagações experimentais que optam por interrogar a personagem desde uma pergunta desestabilizadora: sua condição de mulher. Desde então surgem reinvenções que paradoxalmente convertem esse ícone do nacionalismo em uma figura marginal de matizes pós-modernos. A performance de Evita reveste-se, assim, com as cores estridentes da estética camp e daí surgem imagens surpreendentes de uma Eva travesti, lumpemproletária, festeira, absolutamente marginal às sintaxes explicativas que previamente haviam articulado os discursos tanto da ortodoxia peronista como da oposição liberal" (ROSANO, 2005, p. 274-275, tradução nossa). 
controlado, pois o dramaturgo elide os materiais da Evita revolucionária, trazendo para seu lugar o julgamento e a desqualificação promovidos pelos antiperonistas da década de 1950, segundo Beatriz Sarlo (2005, p. 237).

Caso tomássemos a frase de Martínez ao pé da letra, as possibilidades e os conhecimentos amorosos de Eva no referido drama se restringiriam ao seu derriére. Além de constituir um modo de olhar o mundo, aqui o camp é uma qualidade encontrada no comportamento da protagonista, cuja lembrança do passado tem o poder de transformar a experiência: "não serve de base para um sentimentalismo generoso, e sim para um conhecimento desencantado e cínico da vida" (SARLO, 2005, p. 19). Sem negar a classe média antiperonista de onde provém, e para a qual a mulher de Perón era nada mais do que a intrusa, a prostituta, a ressentida, Copi:

trabalharia com esses discursos da infância e, naturalmente, imprime a eles um tom paródico, mas não no sentido da revolução política, e sim no de um populismo marginal que diz: tudo bem, na Rosada tem uma puta que veste Dior, e daí? (SARLO, 2005, p. 238)

Permitimo-nos discordar parcialmente da ideia de Susan Sontag, de que "Enfatizar o estilo é menosprezar o conteúdo, ou introduzir uma atitude neutra em relação ao conteúdo" 
(1987, p. 320), as deslumbrantes fotografias de Eva Perón em vestido de gala (Cf. Figura 1), que, sendo ou não da Casa Dior, uniam a pompa típica das marchas dos regimes totalitários da década de 1940 ao glamour de divas do cinema, como Dorothy Lamour, María Félix e Rita Hayworth. Os braços à mostra e o discreto decote converteram-se no detalhe interessante que, sem ser rigorosamente intencional, também resulta inevitável:

não atesta obrigatoriamente a arte do fotógrafo; ele diz apenas ou que o fotógrafo se encontrava lá, ou, de maneira mais simplista ainda, que ele não podia não fotografar o objeto parcial ao mesmo tempo que o objeto total. (BARTHES, 1984, p. 76)

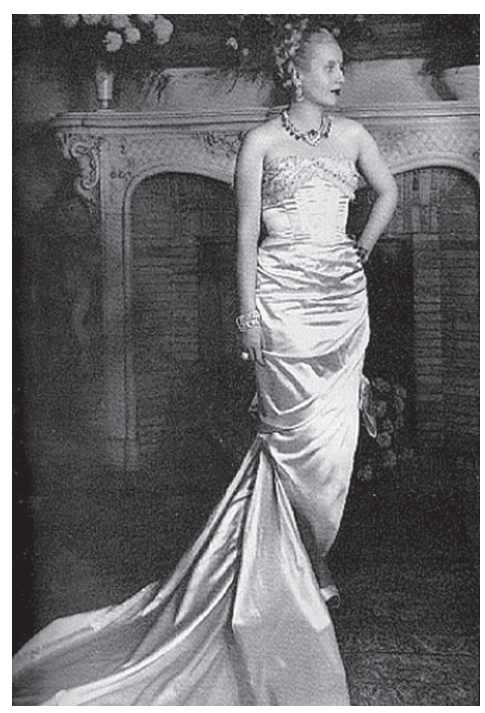

Figura 1 
Esse punctum gracioso, realçado no estilo, na superfície sensual e na textura, vem sendo reproduzido à exaustão nos corpos, celulóides, fotografias e imagens digitais das atrizes que interpretaram Evita - desde Elaine Page a Caroline Bowman na ópera-rock com letra de Tim Rice e música de Andrew Lloyd Weber que, baseada na biografia difamatória The Woman with the Wip [A mulher do chicote] (MAIN, 1952), ganha os palcos do West End londrino, da Broadway novaiorquina e de outras capitais mundiais. O famoso exemplar da fotogenia evitista e da propaganda do populismo peronista configura um biografema homocultural que, como a Eva glorificada por Copi em sua especialidade única e sua força unitária, longe está da "miniatura sentimentalista do kitsch, [...] tem a grandiosidade acessível do melodrama e do camp" (SARLO, 2005, p. 21).

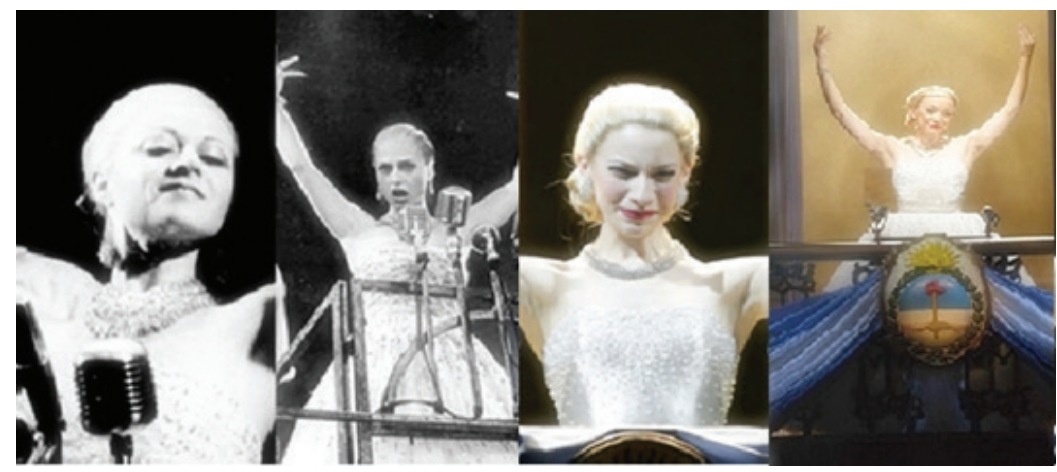

Figura 2: Cantatrizes que interpretaram Evita na ópera-rock: Elaine Page (Inglaterra, 1978-1986); Patti LuPone (Estados Unidos, 19791983); Elena Roger (Estados Unidos, 2006-2007; 2012); Caroline Bowman (Estados Unidos, 2013). 
Em todas as imagens anteriormente reproduzidas, destaca-se o impecável vestuário que, junto à mobília, constitue elemento visual, em grande parte, responsável por caracterizar a arte camp como decorativa por excelência (Cf. SONTAG, 1987, p. 321). Caindo logo nas graças desse gosto, que guarda muita afinidade com o balé clássico, a ópera e o cinema, Eva Perón identifica-se com:

as figuras lânguidas, esguias, sinuosas da pintura e da poesia pré-rafaelita; os corpos delgados, fluidos, assexuados das estampas e dos cartazes Art Nouveau, apresentados em relevo em lâmpadas e cinzeiros; o vazio andrógino que paira na beleza perfeita de Greta Garbo. (SONTAG, 1987, p. 322-323)

Além de se integrar a um círculo no qual cabem a:

melosa e resplandescente feminilidade de Jayne Mansfield, Gina Lollobrigida, Jane Russel, Virginia Mayo; [...] grandes estilistas do temperamento e do maneirismo, como Bette Davis" (SONTAG, 1987, p. 323),

Evita oferece o seu nome e a sua figura à ópera-rock relida nos anos 1990 pelo filme de Alan Parker, cuja protagonista é nada mais, ninguém menos, do que Madonna, uma amante do camp e da androginia.

Como essa, as distintas representações que Eva ganha ao longo do tempo e os papéis desempenhados por ela 
mesma, cada um deles entre aspas, a ser ressignificado, demonstram a epicena conversibilidade da mulher em protagonista; a metáfora da vida como teatro. Nos comícios e comemorações, nas cenas ou nas telas, seus trajes de gala e suas unhas pintadas precisam de uma utilização "como atributo porque, como se sabe, são uma dimensão fundamental da personagem (teatral e política)" (SARLO, 2005, p. 21). Tais atos de teatralizar, ordenar, articular e, de certa forma, isolar-se, integram as funções que Barthes (1990, p. 7-10) verifica nas espécies de línguas diferenciadas, a seu ver, fundadas nas respectivas escritas de Loyola, Fourier e Sade.

A tomar como parâmetro o contexto norte-americano, a cultura homossexual anterior aos protestos de Stonewalll, portanto, precursora dos movimentos gays e lésbicos do final dos anos de 1960, também necessitou do isolamento em guetos que, por outro lado, funcionavam como articulação com outros similares entre si em seus desvios à norma e à "normalidade", dentre os quais se encontram as respostas campy ao "marcadamente atenuado e ao fortemente exagerado" (SONTAG, 1987, p. 322). Alguém, algumas pessoas, determinados grupos, ordenavam formas de resistência à repressão: 
bien fuera en la literatura y el teatro o sencillamente en la creación y el mantenimiento de espacios de sociabilidad y solidaridad (bares, lugares de encuentro, asociaciones, etc.). (ERIBON, 2000, p. 29) ${ }^{3}$

Além de criarem suas gírias e seus jargões nesses locais de socialização, os homossexuais aí formavam e compartilhavam gostos por certas expressões culturais. $\mathrm{O}$ camp, por exemplo, angariou a predileção dos que adotavam como defesa a sua lógica do cru sarcasmo ou da exagerada crueldade e, como meios de diversão, o excesso, a imitação, a repetição e o travestismo. Diversas vezes, a própria presença do homossexual no espaço público pronuncia-se sob a forma da "bicha fechativa", excessiva em sua fala e em seu gestual, enquanto shows de dublagens protagonizados por drag queens, transformistas ou travestis fazem-se bastante comuns nos ambientes gays.

Dentre os mais pronunicados traços campy, o arremedo auxilia-nos a configurar um dos biografemas homoculturais de Evita, fazendo-se notar nos seguintes vestígios da história que, ao mesmo tempo, funcionam como intertextos do universo ficcional de Martínez nos quais aquela

3 "seja na literatura, seja no teatro, ou simplesmente na criação e na manutenção de espaços de sociabilidade e solidariedade (bares, lugares de encontro, associações, etc)" (ERIBON, 2000, p. 29, tradução nossa). 
personalidade é imitada ou imita: a ópera de Tim Rice e Andrew Lloyd Weber; a canção Don't cry for me Argentina nas vozes de Sinnead O'Connor e Janice Brown; os filmes dos quais participara Eva Duarte: La pródiga, La cabalgata del circo e El más infeliz del pueblo). Por sua vez, a Eva Perón do drama de Copi grita para não ser transformada em estátua ou pintura, enquanto seu marido afirma que a imagem dela haverá de ser "reproduzida ao infinito".

Em todos esses casos, não estamos diante do constructo que possibilita meramente distinguir entre sentido literal e simbólico, mas do objeto ou da representação que significa alguma outra coisa ou que é puro artifício:

To camp é uma forma de sedução uma forma que emprega maneirismos extravagantes sujeitos a uma dupla interpretação; gestos cheios de duplicidade, com um significado espirituoso para entendidos e outro mais impessoal, para leigos. Do mesmo modo e por extensão quando a expressão se torna substantivo, quando uma pessoa ou uma coisa é "um Camp", implica uma duplicidade. Por trás do sentido geral "direto" no qual podemos entender alguma coisa, encontramos uma experiência pessoal absurda com esta coisa. (SONTAG, 1987, p. 325)

A repetição própria ao camp atinge o musical Evita, que, constantemente, passa por novas temporadas ao redor do 
mundo (vide Figura 3) e as reproduções do cartaz no qual o desenho do rosto de sua protagonista ornamenta-se com a auréola da Estátua da Liberdade. Tal caracerística parece assimilada pelo autor de Santa Evita quando relaciona uma frase constante nos panfletos que sucederam ao atentado ao teatro parisiense L'Epeé-de-Bois, onde o espetáculo de Copi havia estreado - "Que falta de respeito, que atropelo à boa razão" (MARTÍNEZ, 1996, p. 173) - com o ocorrido a Néstor Perlongher no momento em que, devido à publicação dos três contos de Evita vive,

outros fanáticos invocaram o mesmo tango de [Enrique Santos] Discépolo ao processá-lo por 'atentado ao pudor e profanação': Que falta de respeito, que desplante de maldade insolente. (MARTÍNEZ, 1996, p. 174).

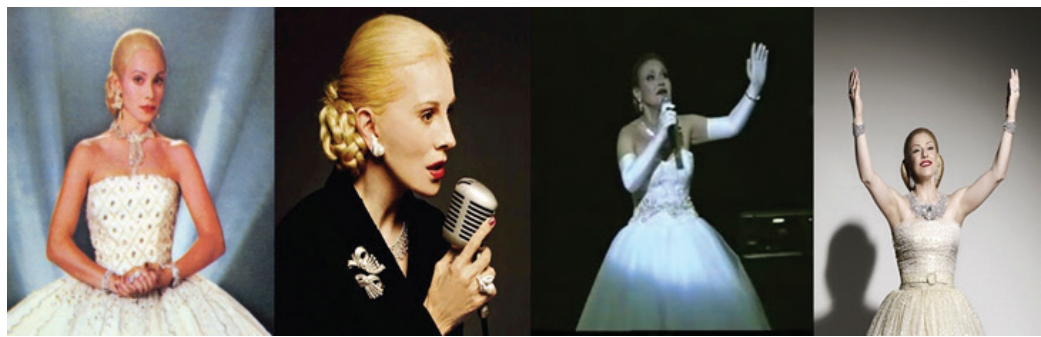

Figura 3: Outras cantatrizes que interpretaram Evita no musical homônimo: Paloma San Basílio (Espanha, 1980-1983); Nacha Guevara (Argentina, 1986); Cláudia (Brasil, 1983); Paula Capovilla (Brasil, 2011).

A intertextualidade encadeada, por meio da qual a narrativa em estudo repete de outra forma uma série de 
obras biográficas, históricas e literárias, substitui a relação autor-texto pela relação leitor-texto: "Alguns dos melhores relatos dos anos 50 são o relato de sua morte" (MARTíNEZ, 1996, p. 172). O mesmo pavor que Eva Perón gerou em vida passaria a ser inspirado pelo espetáculo ao mesmo tempo excitante e perverso de seus funerais que, antecipando o enterro de Judy Garland, outro ícone gay, se tornou capaz de intimidar as elites "com sua intimidade, exagerada, gritante, a malandra, Evita, a deslavada" (MARTínEZ, 1996, p. 172).

Tanto na própria existência, quanto nas vidas post mortem de Eva Perón destacadas neste trabalho, em particular, na pitoresca vida recriada pelo romance em análise, estamos diante do camp ingênuo, puro, sem visível deliberação nem intencionalidade, cujo tom se mantém a despeito do interesse biográfico ou histórico despertado pela primeira dama do peronismo. Para identificarmos o biografema homocultural relacionado àquela sensibilidade, toma relevância o encampamento de sua figura, até hoje parodiada ao infinito por atrizes da grande tela, mulheres na política e travestis dos pequenos shows de pré-noitadas, entreatos ou after-hours que, a cada nova imitação, reacendem a vaidade atribuida à personalidade histórica.

De acordo com Adrián Melo (2005, p. 238), não podemos compreender sua linguagem e sua oratória se não levarmos 
em conta seu passado no radioteatro e na cinematografia argentina. A efervescente atuação no primeiro desses gêneros, quando interpetrou um ciclo de heroínas "exemplares" da história mundial, não por acaso, retorna em seus discursos políticos numa espécie de autoparódia dupla, já que por detrás de muitos deles se encontra o mesmo roteirista e redator, Francisco Muñoz Aspiri (Cf. HAUSSEN, 1997). A agudeza da vida política de Evita conclui-se de forma campy com a exposição pública de sua agonia em meetings do regime e nas inúmeras reproduções que, junto a demonstrações de dó e piedade, multiplicam-se por entre fotos e vídeos da recente televisão nacional.

O romance Santa Evita, contudo, não se revela totalmente campy, só apresenta essa sensibilidade em momentos como os que destacamos, nos quais "revela a inocência, mas também, quando pode, a corrompe" (SONTAG, 1987, p. 326). Sem fazer-se de camp na maior extensão de seu conjunto narrativo, propõe e demonstra uma seriedade que às vezes falha, impossibilitando levar-se a sério determinado grupo de atitudes e de imagens que, para muito além de uma estética ou de um estilo, constituem um repertório dotado de função cultural da maior importância, por exemplo, ao misturar em espaços aparantemente irreconciliáveis o apaixanado, o fantástico e o ingênuo. 
“No Camp há frequentemente algo démesuré na qualidade da ambição, não apenas no estilo da obra em si" (SONTAG, 1987, p. 327), da mesma forma que Eva Perón, na breve vida por ela vivida, expôs com exagero seus luxos, "uma fantasia, um jogo burguês, nada mais, as regras do cerimonial", como canta a protagonista da ópera-rock nela inspirada. Assim também, "el sujeto sexual marginado puede juzgar necesario o ventajoso exagerar la diferencia, disidencia y desviación, lo cual es, en gran parte, el poder significante de la screaming

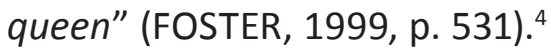

Os mesmos desafios à norma e ao normatizado evidenciam-se nas conhecidas irritações e pirraças de Evita, em "sus lapsus estratégicos com lenguaje de bar y prostíbulo, su negativa a adherirse al protocolo consagrado" (FOSTER, 1999, p. 531). ${ }^{5}$ Essa faceta da personalidade histórica vai acompanhar várias de suas representações biográficas e ficcionais, assim como as faces camp já sublinhadas que, entretanto, parecem rejeitar, embora nunca absolutamente: "tanto as harmonias da seriedade tradicional quanto os riscos da identificação total com estados extremos de sentimento" (SONTAG, 1987, p. 331).

4 "o sujeito sexual marginalizado pode julgar necessário ou vantajoso exagerar a diferença, dissidência e desviação que é, em grande parte, o poder significante da screaming queen [a bichinha cheguei]" (FOSTER, 1999, p. 531, tradução nossa).

5 "seus lapsos estratégicos com linguagem de bar e prostíbulo, sua negativa de aderência ao protocolo consagrado" (FOSTER, 1999, p. 531, tradução nossa). 
Ainda que referendemos a imbricação entre o gosto camp e o gosto dos homossexuais, sua vanguarda e seu público mais articulado, conforme Susan Sontag (1987, p. 334), pensamos que apreciar o sucesso de alguns fracassos, insistir na brincadeira, vencer limitações biológicas, zombar das diferenças de gênero e da própria vida pode não ter nada a ver com uma atitude "descompromissada e despolitizada - pelo menos apolítica" (SONTAG, 1987, p. 320). Preferimos investir na concretude e na história duma sensibilidade capaz de transcender as inércias porventura implicadas nesse seu papel para se afirmar como uma categoria afetiva que firma laços entre as notações culturais e o conjunto não menos diverso das sociedades:

Um viés que passa pela sexualidade, mas vai além da composição de uma subcultura, constituindo-se mesmo num imaginário ou regime de imagens relevante na contemporaneidade. (LOPES, 2000, p. 150-151)

Nesse trânsito por uma fração da imagética de Eva Perón, a mutabilidade percebida no camp, materializada mesmo no cadáver mumificado do ser histórico e das personagens nele baseadas, faz notar a passagem do tempo numa espécie bem platina de nostalgia. Assim enxergamos, no "isso foi" do movimento gay argentino pós-ditatorial, esperançosa 
ligação entre homossexualidade e política agora esvaída em meio "ao isso nunca mais será o mesmo", no qual ressaltam a cooptação das subjetividades desviantes, o aliancismo de uma parte da teoria cultural com as políticas de direita, a heteronormatividade dos meios de comunicação e os apelos do mercado de consumo. Não era mesmo aos casais homotelevisivos, refiltrados pelo padrão global, mas às bichas de todos os paraísos perdidos que Martínez assim se referia: "Elas a possuem, a apalpam, se entregam a ela. Mas afinal de contas, não foi isso que Evita pediu que o povo fizesse com sua memória?" (1996, p. 175).

\section{REFERÊNCIAS}

BARTHES, Roland. Câmara clara. Trad. por Júlio Castañon Guimarães. Rio de Janeiro: Nova Fronteira, 1984. . Sade, Fourier, Loyola. Trad. de Mário Laranjeira. São Paulo: Brasiliense, 1990.

DOSSE, François. La apuesta biográfica: escribir una vida. Valencia: EdUV, 2007.

ERIBON, Didier. Identidades: reflexiones sobre la cuestión gay. Trad. Por José Miguel Marcén. Barcelona: Bellaterra, 2000.

FOSTER, David William. Evita, Juan José Sebreli y género. In: Revista Canadiense de Estudios Hispánicos (RCEH). Edmond, Canadá, p. 529-37, Spring; 23 mar. 1999.

HAUSSEN, Doris Fagundes. Rádio e política: tempos de Vargas e Perón. Porto Alegre: EDIPUCRS, 1997.

JAUMANDREU, Paco. La cabeza contra el suelo: memorias. Buenos Aires: Corregidor, 1981 [1975]. 
. Evita fuera del balcón. Buenos Aires: Ediciones del Libro Abierto, 1981.

LAMBORGHINI, Osvaldo. El fiord. Buenos Aires: Chinatown, 1969.

LOPES, Denilson. Somos todos travestis (Imaginário camp e a crise do individualismo). In: Lugar Comum (UFRJ), Rio de Janeiro, n. 9/10, p. 147159, 2000.

. Terceiro manifesto Camp. In: LOPES, Denilson. O homem que amava rapazes e outros ensaios. Rio de Janeiro: Aeroplano, 2002. p. 89120;

MAIN, Mary. The Woman with the Whip: Eva Perón. Garden City, N.Y.: Doubleday, 1952.

MARTínEZ, Tomás Eloy. Santa Evita. Trad. por Sergio Molina. São Paulo: Companhia das Letras, 1996.

MELO, Adrián. El amor de los muchachos: homosexualidad \& literatura. Buenos Aires: Lea, 2005.

PERLONGHER, Néstor. Evita vive (1975). El cadáver (1980). Joyas macabras (1983). El cadáver de la nación (1989). In: PERLONGHER, Néstor. Prosa plebeya. Selección y prólogo de Christian Ferrer y Osvaldo Balgorria. Buenos Aires: Colihue, 2008. p. 191-208.

PUIG, Manuel. La tajada. In: AMÍCOLA, José (Ed). Materiales iniciales para 'La traición de Rita Hayworth'. La Plata: Centro de Estudios de Teoría y Crítica Literaria, Universidad Nacional de La Plata, 1966.

ROSANO, Susana. Rostros y máscaras de Eva Perón: imaginario populista y representación (Argentina, 1951 - 2003). Doctoral Dissertation, Universityof Pittsburgh. 2003.

SARLO, Beatriz. A paixão e a exceção: Borges, Eva Perón, Montoneros. São Paulo: Companhia das Letras; Belo Horizonte: EdUFMG, 2005.

. Una modernidad periférica: Buenos Aires 1920 y 1930. Buenos Aires: Nueva Visión, 1988.

SEBRELI, Juan José. Eva Perón, ¿aventurera o militante? Buenos Aires: Editorial Siglo XX, 1966. 
SONTAG, Susan. Camp - algunas notas. In: SONTAG, Susan. Contra a interpretação e outros ensaios. Tradução de Ana Maria Capovilla. Porto Alegre: L\&PM, 1987. p. 315-336.

SOUZA, Eneida Maria de. Crítica cult. Belo Horizonte: EdUFMG, 2002.

TABORDA, Raúl Natalio Roque Damonte Botana (Copi). Eva Perón. Trad. Jorge de Monteleone. Buenos Aires, Adriana Hidalgo, 2000 [1970].

WALSH, María Elena. Eva. In: Canciones contra el mal de ojo. Buenos Aires: Sudamericana, 1976.

André Luis Mitidieri é graduado em Letras pela Universidade da Região da Campanha (URCAMP) e em História pela Universidade Regional do Alto Uruguai e das Missões (URI-FW). Mestre e doutor em Letras, área de concentração em Teoria da Literatura, pela PUCRS. Professor Titular no Curso de Letras da Universidade Estadual de Santa Cruz (UESC). Docente Efetivo de Literatura e História no PPGL - Mestrado em Linguagens e Representações - na mesma instituição. Docente colaborador junto ao Mestrado em Literatura Comparada da URI-FW. Consultor ad-hoc da CAPES. Membro da Associação Brasileira de Literatura Comparada (ABRALIC), da Associação Brasileira de Hispanistas (ABH) e da Associação Internacional de Lusitanistas (AIL). Integrante do GT Homocultura e Linguagens da Associação Nacional de Pós-Graduação e Pesquisa em Letras e Linguística (ANPOLL). Email: almpereira@uesc.br 